\title{
The Emerging Workforce of International University Student Workers: Injury Experience in an Australian University
}

\author{
Yahya Thamrin ${ }^{1,2}$ (1), Dino Pisaniello ${ }^{2, *}$, Cally Guerin ${ }^{3}$ and Paul Rothmore ${ }^{2}$ (1) \\ 1 Department of Occupational Safety and Health, Faculty of Public Health, Hasanuddin University, \\ Makassar 90245, Indonesia; yahyathamrin@yahoo.com \\ 2 School of Public Health, Faculty of Health and Medical Sciences, University of Adelaide, Adelaide 5005, \\ Australia; paul.rothmore@adelaide.edu.au \\ 3 Faculty of Arts, University of Adelaide, Adelaide 5005, Australia; cally.guerin@adelaide.edu.au \\ * Correspondence: dino.pisaniello@adelaide.edu.au; Tel.: +61-8-83133571
}

Received: 11 January 2018; Accepted: 1 March 2018; Published: 6 March 2018

\begin{abstract}
International university students are a growing section of the workforce and are thought to be at greater risk of injury. Qualitative studies have highlighted vulnerabilities, but there is a shortage of quantitative research exploring the injury experience and associated risk factors of this emerging issue. In this study, a total of 466 university student workers across a range of study programs in a single Australian university completed an online survey, with questions relating to their background, working experience, training and injury experience. Risk factors for injury were explored in a multivariate statistical model. More than half had not received any safety training before they started work, and 10\% reported having had a work injury. About half of these injuries occurred after training. Statistically significant risk factors for injury included working more than $20 \mathrm{~h}$ per week (adjusted odds ratio 2.20 (95\% CI 1.03-4.71) and lack of confidence in discussing safety issues (AOR 2.17; 95\% CI 1.13-4.16). The findings suggest the need for a more engaging and effective approach to safety education and a limit on working hours. This situation is a moral challenge for universities, in that they are effectively sponsoring young workers in the community. It is recommended that longitudinal studies of international student workers be conducted.
\end{abstract}

Keywords: international students; university; worker; injury; risk factor

\section{Introduction}

International (foreign) students represent a significant and rising proportion of young workers in many countries. In 2016, there were over 300,000 international students enrolled in the higher education sector in Australia, a 13\% increase over the previous year [1]. At the same time, international students may be at greater risk for occupational injury than their domestic peers [2]. Their vulnerability may be due to cultural and language barriers, fewer work choices, relatively poorer working conditions and, in many cases, financial pressures [3-5]. As such, they pose an emerging challenge for occupational health and safety (OHS) regulators.

A number of studies have explored students' and international students' vulnerability in the workplace [4,6,7]. These have been essentially qualitative. Nyland and coworkers [4] have highlighted exploitation (not attributed to racism), limited understanding by students of rights and support services, the need for education suppliers to provide relevant information and appropriate regulation. Anderson and coworkers [3] concluded that international student working experiences were similar to those of migrant workers, including their experience of illegal work. Ou and Thygerson [8] examined occupational injuries among university student employees using a quantitative approach but did not 
differentiate international students. This study found that heavy workload, work stress, and physical hazards exposure were the main contributing factors to injuries among university student workers.

The profile of young workers' injury experience may be gleaned from worker compensation statistics [9]. However, there is no specific occupational code for international students, and underreporting for young workers, particularly females, is also a potential issue. Population survey methods are an alternative and more sensitive indicator of injury experience [10].

There is scarcity of quantitative research on international students' working experience and training experience, together with the risk factors of injury among this sub-group of young workers.

Using a quantitative online survey approach, the aims of this study were to describe jobs, safety training, injuries and associated risk factors for international university student workers. This information will assist universities in raising awareness of student worker safety issues and in the development of appropriate interventions.

\section{Methods}

Rather than survey student workers in their workplaces, students were sampled in a familiar and common environment-namely a University portal. By preserving anonymity, we considered that students would be more likely to share information about themselves, their experiences and perceptions about safety at work.

\subsection{Study Design and Data Collection}

An online questionnaire, in a cross-sectional study design, was used for data collection. The survey of international students was conducted at the University of Adelaide using SurveyMonkey software (SurveyMonkey Inc., Palo Alto, CA, USA) in the second half of 2014. As there was no previously published survey instrument for international students, the questionnaire was designed in collaboration with the International Students Centre (ISC) of the University. After a pilot with a number of international students ( $n=29$, across a range of faculties) for intelligibility and logical flow, a survey invitation with its online link was distributed by the ISC to all international students at the University. The survey invitations were sent in two waves. In the first wave, the invitations were sent to the international students' email address with the subject heading "Invitation for survey for international students". This email included the survey information sheet, a consent form and the survey questionnaire. A follow-up, reminder email, was sent three weeks later.

The survey was approved by the University of Adelaide Human Research Ethics Committee (Approval number HS-2013-045). The questionnaire is available as Supplementary Materials.

\subsection{Participants}

Information about the survey indicated that it was only for enrolled international students who had experience of working while studying in Australia. Both undergraduate and postgraduate students were eligible.

\subsection{Statistical Methods}

Microsoft Excel Software (Microsoft Corporation, Redmond, WA, USA) was used for descriptive statistics. The IBM Statistical Package for the Social Sciences (SPSS) Version 21 (IBM Corporation, Armonk, NY, USA) was used for analytical statistics. The principal outcome variable in the study was student injury experience ("Have you ever had an injury at work while studying in Australia?"). Twenty independent variables, categorised into demographic factors, academic factors, working experiences and safety training experiences were assessed in terms of their association with the outcome variable of injury experience.

Bivariate analysis using chi-square test (a two-tailed $p$-value of 0.05 ) and odds ratios (OR) were performed to determine the association between variables. Independent variables that were statistically 
significant and associated with the outcome variable in the bivariate analysis were included in a multivariate logistic regression model to identify important predictor factors.

\section{Results}

The University of Adelaide is a medium-sized university with approximately $26 \%$ international students (approximately 5500 in 2015) [11].

Seven hundred and nineteen students took part in the survey, generating 466 complete responses. Only complete responses were used for data analysis. The majority of respondents came from China, Malaysia, Indonesia and Vietnam.

\subsection{Descriptive Analysis}

Table 1 presents information on international student participant demographics, enrolment and financial factors, working experiences and safety training experiences and injury experiences.

Table 1. International student worker characteristics and experiences.

\begin{tabular}{|c|c|c|}
\hline Characteristic Data & Number of Students & $\%$ of Total Respondents $(n=466)$ \\
\hline \multicolumn{3}{|l|}{ Student demographics } \\
\hline \multicolumn{3}{|l|}{ Mean age 24.9 years, median age 24 years } \\
\hline Females & 246 & 52.8 \\
\hline Married & 85 & 18.2 \\
\hline Have children & 53 & 11.4 \\
\hline Have family members with them & 100 & 21.5 \\
\hline \multicolumn{3}{|l|}{ Academic factors } \\
\hline \multicolumn{3}{|l|}{ Faculty: } \\
\hline Engineering, Computer and Mathematics & 124 & 26.6 \\
\hline Health Sciences & 44 & 9.40 \\
\hline Humanities and Social Sciences & 39 & 8.40 \\
\hline Sciences & 75 & 16.1 \\
\hline The Professions & 184 & 39.5 \\
\hline \multicolumn{3}{|l|}{ Study program: } \\
\hline Undergraduate & 171 & 36.7 \\
\hline Study Abroad or Exchange program & 50 & 10.7 \\
\hline Master & 190 & 40.8 \\
\hline PhD & 55 & 11.8 \\
\hline \multicolumn{3}{|l|}{ Years into study program: } \\
\hline 1st year & 151 & 32.4 \\
\hline 2nd year & 157 & 33.7 \\
\hline 3rd year & 85 & 18.2 \\
\hline 4 th year & 73 & 15.7 \\
\hline \multicolumn{3}{|l|}{ Financial support: } \\
\hline Private & 323 & 69.3 \\
\hline Partial scholarship & 31 & 6.70 \\
\hline Full scholarship & 112 & 24.0 \\
\hline \multicolumn{3}{|l|}{ Working experiences } \\
\hline More than one job & 56 & 12.0 \\
\hline \multicolumn{3}{|l|}{ Sector of industry: } \\
\hline Restaurant & 247 & 42.1 \\
\hline Supermarket/grocery/shop & 124 & 21.1 \\
\hline Cleaning & 74 & 12.6 \\
\hline Agriculture & 34 & 5.8 \\
\hline Perception of wages (not fair) & 199 & 42.7 \\
\hline Working more than $20 \mathrm{~h} /$ week & 60 & 12.9 \\
\hline Outdoor workers & 36 & 7.7 \\
\hline Not working under supervision & 142 & 30.5 \\
\hline
\end{tabular}


Table 1. Cont.

\begin{tabular}{lcc}
\hline \multicolumn{1}{c}{ Characteristic Data } & Number of Students & \% of Total Respondents $(\boldsymbol{n}=\mathbf{4 6 6})$ \\
\hline Safety training experiences & & \\
\hline No safety training & 286 & 61.4 \\
No assessment for training & 61 & 34.1 \\
\hline Injury experiences & & \\
\hline Any injury & 48 & 40.3 \\
After safety training & 21 & 56.3 \\
Before safety training & 27 & \\
\hline Other & & 42.3 \\
\hline Lacking confidence in discussing safety & 197 & \\
\hline
\end{tabular}

\subsubsection{Working Experiences}

More than $50 \%$ of respondents were engaged in part-time work and approximately $39 \%$ of the participants had experience in casual jobs. Only $5.4 \%$ of this group had been involved in seasonal employment.

More than $42 \%$ of participants reported that they had working experiences in the restaurant sector. There were $21.1 \%$ in the supermarket/grocery/shop sector, followed by the cleaning and agriculture sectors, with percentages at $12.6 \%$ and $5.8 \%$, respectively. Approximately $18 \%$ of respondents revealed that they worked in another category, including education, human services, medical, nursing home, tutorial, education, university, hotel, marketing, accounting, sales and dental clinics.

Turning to working hours, the vast majority of students worked less than $20 \mathrm{~h}$ per week; only $12.9 \%$ of them devoted $20 \mathrm{~h}$ or more per week to the workplace.

\subsubsection{Safety Training Experiences}

With respect to training, $61 \%$ had not received any safety training before they started work. Amongst the remaining 39\% who had received training from one or more sources, the university was the main provider (50\%), followed by the workplace $(41 \%)$, high school $(9 \%)$ and technical college (TAFE) (10\%). Of the 179 who had received training, 61 (34\%) had no assessment. Regarding the format of safety training, $72 \%$ reported face-to-face safety training, $31 \%$ paper-based, $28 \%$ computer-based and $19 \%$ video-based training.

\subsubsection{Injury Experiences}

It can be seen from Table 1 that 48 students $(10.3 \%)$ had experienced an injury in the workplace. More than $43 \%$ of these individuals experienced the injury after completing safety training.

Half of the students reporting a work injury had experienced only one injury. About $21 \%$ of students recorded that they had been injured twice, and two percent had experienced work injuries on three occasions. Cuts and lacerations were the most common injury type $(70 \%)$, followed by burns $(38 \%)$, strains $(17 \%)$ and injuries from slips/falls $(17 \%)$.

\subsection{Factors Associated with Injury Experiences}

Table 2 provides information regarding the relationship between twenty independent variables and reported injury experience as the outcome variable. This table indicates there was a positive association between injury experience and being in the second year of study, with an unadjusted odds ratio (OR) of 3.06, 95\% confidence interval (CI) 1.27-7.35.

Other significant associations with injury were: a perception of unfair wages, (OR of $2.71,95 \%$ CI 1.45-5.06); working $20 \mathrm{~h}$ or more per week, (OR 2.57, 95\% CI 1.25-5.28); and lack of confidence in discussing safety issues, (OR 2.61, 95\% CI 1.40-4.88). 
Potential injury predictor variables found to be significant in the bivariate analysis were included in a logistic regression model generating adjusted odds ratios (AOR). It can be seen from Table 2 that there remained a significant association between international students' injury experiences and being in the second year of study (AOR 2.69, 95\% CI 1.04-6.96); having a perception of unfair wages (AOR 2.42, 95\% CI 1.24-4.71); working $20 \mathrm{~h}$ or more per week (AOR 2.20, 95\% CI 1.03-4.71); and lack of confidence in discussing safety issues (AOR 2.17, 95\% CI 1.13-4.16).

Table 2. Predictors of injury experience among international student workers.

\begin{tabular}{|c|c|c|c|c|}
\hline \multirow{3}{*}{ Independent Variables } & \multicolumn{4}{|c|}{ Injury Experience } \\
\hline & \multicolumn{2}{|c|}{ Unadjusted } & \multicolumn{2}{|c|}{ Adjusted } \\
\hline & OR & $95 \% \mathrm{CI}$ & OR & $95 \% \mathrm{CI}$ \\
\hline \multicolumn{5}{|l|}{ Student demographics } \\
\hline Age ( $>24$ years), median split & 1.16 & $0.63-2.13$ & & \\
\hline Gender (being female) & 0.97 & $0.53-1.76$ & & \\
\hline Marital status (married) & 0.88 & $0.39-1.97$ & & \\
\hline Have children & 1.13 & $0.46-2.79$ & & \\
\hline Have family members with them & 0.83 & $0.39-1.77$ & & \\
\hline \multicolumn{5}{|l|}{ Academic factors } \\
\hline \multicolumn{5}{|l|}{ Faculty: } \\
\hline Engineering, Computer and Mathematics & \multicolumn{2}{|c|}{1.00} & & \\
\hline Health sciences & 2.27 & $0.94-5.49$ & & \\
\hline Humanities and Social Sciences & 2.85 & $0.65-12.61$ & & \\
\hline Sciences & 0.75 & $0.28-1.98$ & & \\
\hline The Professions & 0.79 & $0.36-1.72$ & & \\
\hline \multicolumn{5}{|l|}{ Year of study: } \\
\hline 1st year & \multicolumn{2}{|c|}{1.00} & & \\
\hline 2nd year & $3.06 *$ & $1.27-7.35$ * & $2.69 *$ & $1.04-6.96 *$ \\
\hline 3rd year & 1.78 & $0.82-3.90$ & & \\
\hline 4 th year & 2.09 & $0.81-5.36$ & & \\
\hline \multicolumn{5}{|l|}{ Study program: } \\
\hline Undergraduate & \multicolumn{2}{|c|}{1.00} & & \\
\hline Study Abroad or Exchange program & 0.91 & $0.32-2.58$ & & \\
\hline Master & 1.57 & $0.36-6.92$ & & \\
\hline $\mathrm{PhD}$ & 0.73 & $0.26-2.01$ & & \\
\hline \multicolumn{5}{|l|}{ Financial support: } \\
\hline Private & \multicolumn{2}{|c|}{1.00} & & \\
\hline Partial scholarship & 1.57 & $0.74-3.36$ & & \\
\hline Full scholarship & 0.72 & $0.22-1.84$ & & \\
\hline \multicolumn{5}{|l|}{ Working experiences } \\
\hline Number of jobs (more than 1 ) & 1.28 & $0.55-3.02$ & & \\
\hline Sector of industry: & & & & \\
\hline Restaurant & \multicolumn{2}{|c|}{1.00} & & \\
\hline Supermarket/grocery/shop & 0.51 & $0.12-2.26$ & & \\
\hline Cleaning & 0.64 & $0.14-3.04$ & & \\
\hline Agriculture & 0.52 & $0.10-2.58$ & & \\
\hline Perception of wages (not fair) & $2.71 *$ & $1.45-5.06^{*}$ & $2.42 *$ & $1.24-4.71$ * \\
\hline Working hours/week (20 or more) & $2.57 *$ & $1.25-5.28$ * & $2.20 *$ & $1.03-4.71$ * \\
\hline Working condition (outdoor) & 0.91 & $0.31-2.70$ & & \\
\hline Not working under supervision & 0.93 & $0.48-1.80$ & & \\
\hline \multicolumn{5}{|l|}{ Safety training experiences } \\
\hline No safety training & 1.44 & $0.76-2.72$ & & \\
\hline No assessment for training & 2.42 & $0.83-7.01$ & & \\
\hline Lacking confidence in discussing safety & $2.61 *$ & $1.40-4.88^{*}$ & $2.17^{*}$ & $1.13-4.16^{*}$ \\
\hline
\end{tabular}

* Statistically significant, $p<0.05$; Statistically significant for bivariate analysis; Statistically significant for multivariate analysis. 


\section{Discussion}

This is the first study to examine injury experience and its predictive factors among an increasing and vulnerable workforce of international student workers using a quantitative approach.

The discrepancy in the number of participating students and the number of complete responses occurred for two reasons. Firstly, the online survey allowed participants to skip questions for which they were unwilling to share information Secondly, although the online information indicated that the survey was only for those with working experiences, international students could participate in the online survey whether they had this experience or not. Participants who lacked this experience could not complete all the questions. Thus, only those respondents with complete responses (466) were included in the analysis. It is important to mention that there were some questions that allowed respondents to choose more than one option. Hence, in some cases total responses exceed 466.

\subsection{International Students' Working Conditions}

This study found that most international students worked in a part-time job (55.3\%), as distinct from casual $(39.2 \%)$ and seasonal (5.4\%). Most of the respondents worked in the restaurant supermarket, and cleaning industries; more than $90 \%$ of them worked indoors.

The findings are consistent with the qualitative studies of Nyland and coworkers [4] and Anderson and coworkers [6], both of whom maintained that a large number of international students work in the restaurant sector and other sectors that are commonly undesired by local employees. More broadly, the literature suggests that such workers frequently undertake low-status jobs, and work in substandard conditions. In addition, they may be susceptible to exploitation, since in many cases these workers are facing financial problems and lack a comprehensive understanding of safety arrangements in Australia [12].

However, this study found that a small percentage of international students (13\%) worked $20 \mathrm{~h}$ or more per week, which is stated as the maximum work commitment outside of study allowable under their visa conditions. In a recent survey of temporary migrant workers in Australia, Berg and Farbenblum found working hours for international students to be similar to those observed in this study [13]. This finding is not consistent with Anderson and coworkers [14], which indicated that many international student workers in the UK breach their visa conditions or "bend the rules" for working over $20 \mathrm{~h}$ a week in illegal employment sectors. The reason for the different results between the UK study and the Australian study is not clear and needs further research.

\subsection{Lack of Safety Training Experiences}

Turning to safety training experience, the findings of this study provide important insights into the effectiveness of international students' safety training experiences. Although provision of safety induction training is a legal requirement; more than $60 \%$ of the participants claimed that they did not receive any safety training before commencing work.

Unfortunately, more than $40 \%$ of students with training experienced injury after having safety training, indicating that the training may well have been inadequate. Relatedly, the results from bivariate analysis (Table 2) indicate that safety training experience was not significantly associated with injury. This is consistent with Zierold and Anderson [15], who claimed that safety training was not significantly associated with severe injuries among young workers.

These findings, and the observation that only $58 \%$ of international students were confident in discussing safety matters, beg the question of the effectiveness of both university and workplace safety training for international students.

It is widely assumed that educational programs have the potential to foster safety knowledge among students [16,17]. However, from the evidence in this study, it cannot be assumed that simply providing safety knowledge will automatically lead to the adoption of safe behaviour and a subsequent reduction of injuries in the workplace [18]. In line with Blair and coworkers [19], the current 
study strengthens calls for safety education and training to be more effective in influencing safety attitudes and behaviours. Additionally, this research suggests that more can be done to improve university-industry awareness with respect to safety training [18].

\subsection{Injury Experience and Important Predictive Factors}

Cuts and burns were the most common injuries. This is to be expected, since most of participants worked in the restaurant sector and the retail trade. Brosnan and Loudoun [20] reported that more than half of the teenage Australian labour force were employed in retail, accommodation, cafés and restaurants, where cuts and burns are often the result of processing, packing, cooking and serving.

Four independent variables were found to be statistically significantly associated with students' injury experiences: namely being in the second year of study (AOR 2.69); perceived unfair wages (AOR 2.42); working $20 \mathrm{~h}$ or more (AOR 2.20); and lacking confidence in discussing safety issues (AOR 2.17).

With regard to year of study, there appear to be no comparable findings in the literature specific to international students. However, according to Gohn and coworkers [21], the main factors that may influence attrition of second year students include adjustment to stress, grade satisfaction, time management and financial management. Thus, it is plausible that students in their second year of study may be at greater risk than other students. However, it is more likely that the accident/injury occurred in the first year of study but was reported in the second year when the survey was conducted. The phenomenon of injuries occurring more frequently in unfamiliar environments is well recognized. Perception of wage unfairness $(43 \%)$ was a significant predictive factor. While not explicit in our survey, it is likely that perceptions of wage unfairness and working hours may be associated with low levels of job satisfaction. Previous studies have reported that those who were dissatisfied with their work were almost three times more likely to report pain and four times more likely to experience an injury $[22,23]$.

Focusing on weekly working hours, the findings are consistent with the US research about occupational injuries among university students, specifically, that a heavy workload is a risk factor for student employees experiencing one or more occupational injuries [8].

Our previous research with incoming university students in South Australia showed a significant association between safety training and skill and confidence in discussing safety issues [2]. Looking solely at international students, it is now revealed that students who are less confident about discussing safety issues are twice as likely to have experienced a workplace injury (AOR 2.17).

One limitation of this study is that it was conducted in only one university, and at one point in time. However, the characteristics of international students at the University of Adelaide are similar to international students elsewhere in Australia [24]. Furthermore, it was not possible to determine the actual proportion of international students at the University of Adelaide with work experience in Australia, and thus eligible for inclusion. We were also unable to determine the severity of injury and consequences of the injury. Finally, we were unable to establish a causal relationship due to the cross-sectional nature of our study.

\section{Conclusions}

Firstly, it can be concluded that many, if not most, international students do not receive any safety training before commencing work. Secondly, for those who do have training, a significant proportion do go on to have an injury. Thirdly, it is evident that many international students lack confidence in discussing safety matters, which may include reporting of hazards, injuries or symptoms. These three findings suggest the need for a more engaging, effective and perhaps culturally sensitive approach to safety education for international student workers. This is also a moral challenge for universities, in that they are effectively sponsoring young workers in the community, and have a duty of care beyond discipline-specific education. 
Finally, working more than $20 \mathrm{~h}$ per week appears to double the risk of workplace injury. There is a need to raise awareness of the safety issues associated with non-compliance with visa conditions on working hours.

It is recommended that longitudinal studies of international student workers be conducted, and the impacts of workplace injuries be investigated, in order to prevent injuries among this increasing large, and emerging, section of the workforce.

Supplementary Materials: The following are available online at http://www.mdpi.com/1660-4601/15/3/456/s1, Survey questionnaire: International Students as Young Migrant Workers in South Australia: The Role of the University in OHS Awareness and Education.

Acknowledgments: The authors would like to thank Patricia Anderson, Manager of the International Student Centre (ISC) at the University of Adelaide, for her help in distributing the survey invitation. For assistance with statistical analyses, we thank Jianjun Xiang. We thank SafeWork SA for a supplementary scholarship for Yahya Thamrin.

Author Contributions: Yahya Thamrin developed the survey instrument, undertook data collection, performed the statistical analyses and was the lead writer; Dino Pisaniello conceptualized the study, assisted with writing the manuscript and revised the manuscript critically; Cally Guerin assisted with conceptualizing the study, assisted with writing the manuscript and revised the manuscript critically; Paul Rothmore reviewed the data, assisted with writing the manuscript and revising the manuscript critically.

Conflicts of Interest: The authors declare no conflict of interest.

\section{References}

1. Department of Education and Training. International Student Data 2016. Available online: https:// internationaleducation.gov.au/research/International-Student-Data/Pages/InternationalStudentData2016. aspx (accessed on 24 April 2017).

2. Thamrin, Y.; Pisaniello, D.; Stewart, S. Time trends and predictive factors for safety perceptions among incoming South Australian university students. J. Saf. Res. 2010, 41, 59-63. [CrossRef] [PubMed]

3. Anderson, D.; Lamare, R.; Hanniff, Z. The working experiences of student migrants in Australia and New Zealand. In Young People and Work; Price, R., McDonald, P., Bayle, J., Pini, B., Eds.; Ashgate Publishing Ltd.: Surrey, UK, 2011; pp. 51-66.

4. Nyland, C.; Forbes-Mewett, H.; Marginson, S.; Ramia, G.; Sawir, E.; Smith, S. International student-workers in australia: A new vulnerable workforce. J. Educ. Work 2009, 22, 1-14. [CrossRef]

5. UKCOSA. International Students in UK Universities and Colleges: Broadening Our Horizons. Available online: http://heer.qaa.ac.uk/SearchForSummaries/Summaries/Pages/SCEE142.aspx (accessed on 26 February 2017).

6. Anderson, D.; Hannif, Z.; Lamm, F. The good, the bad and the ugly: The health and safety of young workers. In Young People and Work; Price, R., McDonald, P., Bayle, J., Pini, B., Eds.; Ashgate Publishing Ltd.: Surrey, UK, 2011; pp. 87-103.

7. McDonald, P.; Bailey, J.; Oliver, D.; Pini, B. Compounding vulnerability? Young workers' employment concerns and the anticipated impact of the workchoices act. Aust. Bull. Labour 2007, 33, 60-88.

8. Ou, J.; Thygerson, S.M. Risk factors for work-related injuries among university student employees. Ind. Health 2012, 50, 445-449. [CrossRef] [PubMed]

9. Jahan, N.; Pisaniello, D.; Stewart, S.; Braunack-Mayer, A.; Winefield, H. Young worker injury experience in South Australia 1998-2007. Public Health Bull. 2010, 7, 53-55.

10. Safe Work Australia. Work-Related Injuries in Australia, 2005-2006. Available online: https: //www.safeworkaustralia.gov.au/system/files/documents/1702/comparisonofcompensationdata_ allincurredworkrelatedinjuries_2009_pdf.pdf (accessed on 29 September 2016).

11. The University of Adelaide. 2015 Annual Report. Available online: https://www.adelaide.edu.au/ publications/pdfs/a-report-15.pdf (accessed on 4 November 2016).

12. Collie, A.; Sampson, A. Inquiries into Migrant Rights Show Same Old Problems-But We Already Have Solutions. Available online: http:/ / theconversation.com/inquiries-into-migrant-worker-rights-show-sameold-problems-but-we-already-have-solutions-46683 (accessed on 3 February 2017). 
13. Berg, L.; Farbenblum, B. Wage Theft in Australia-Findings of the National Temporary Migrant Survey. Migrant Worker Justice Initiative. Available online: https://www.mwji.org/publications/ (accessed on 28 June 2017).

14. Anderson, B.; Ruhs, M.; Rogaly, B.; Spencer, S. Fair Enough? Central and Eastern European Migrants in Low-Wage Employment in the UK; Joseph Rowntree Foundation: York, UK, 2006.

15. Zierold, K.M.; Anderson, H.A. Severe injury and the need for improved safety training among working teens. Am. J. Health Behav. 2006, 30, 525-532. [CrossRef] [PubMed]

16. Lerman, Y.; Feldman, Y.; Shnaps, R.; Kushnir, T.; Ribak, J. Evaluation of an occupational health education program among 11th grade students. Am. J. Ind. Med. 1998, 34, 607-613. [CrossRef]

17. Linker, D.; Miller, M.E.; Freeman, K.S.; Burbacher, T. Health and safety awareness for working teens: Developing a successful, statewide program for educating teen workers. Fam. Community Health 2005, 28, 225-234. [CrossRef] [PubMed]

18. Pisaniello, D.L.; Stewart, S.K.; Jahan, N.; Pisaniello, S.L.; Winefield, H.; Braunack-Mayer, A. The role of high schools in introductory occupational safety education-Teacher perspectives on effectiveness. Saf. Sci. 2013, 55, 53-61. [CrossRef]

19. Blair, E.H.; Seo, D.C.; Torabi, M.R.; Kaldahl, M.A. Safety beliefs and safe behavior among midwestern college students. J. Saf. Res. 2004, 35, 131-140. [CrossRef] [PubMed]

20. Brosnan, P.A.; Loudoun, R.J. Labour market experiences of teenage Australian workers in the 21st century. In Proceedings of the 20th Conference of the Association of Industrial Relations Academics in Australia and New Zealand (AIRAANZ), Adelaide, Australia, 1-3 February 2006.

21. Gohn, L.; Swartz, J.; Donnelly, S. A case study of second year student persistence. J. Coll. Stud. Retent. Res. Theory Pract. 2001, 2, 271-294. [CrossRef]

22. Stewart, S.K.; Rothmore, P.R.; Doda, D.V.; Hiller, J.E.; Mahmood, M.A.; Pisaniello, D.L. Musculoskeletal pain and discomfort and associated worker and organizational factors: A cross-sectional study. Work 2014, 48, 261-271. [PubMed]

23. Rothmore, P.; Aylward, P.; Gray, J.; Karnon, J. A long-term evaluation of the stage of change approach and compensable injury outcomes-A cluster randomized trial. Ergonomics 2017, 60, 628-635. [CrossRef] [PubMed]

24. Aumann, H.; Pisaniello, D.; Lee, S.G.; Sibly, J. A survey of the OHS experiences and perceptions of Australian university student. J. Occup. Health Saf. Aust. N. Z. 2007, 23, 259-265. 